\title{
The importance of adrenal venous sampling in ACTH-independent Cushing syndrome: A case report and literature review
}

\author{
RALUCA TULIN ${ }^{1,2}$, ADRIAN TULIN $^{3,4}$, LUMINITA FLORENTINA TOMESCU $^{5}$, ENYEDI MIHALY $^{3}$, \\ ADELAIDA AVINO $^{6,7}$, BOGDAN SOCEA ${ }^{8,9}$, CRISTIAN-RADU JECAN ${ }^{6,7}$, \\ OVIDIU STIRU ${ }^{10,11}$ and RADU-IULIAN SPATARU ${ }^{12,13}$
}

\author{
${ }^{1}$ Department of Embryology, Faculty of Medicine, 'Carol Davila' University of Medicine and Pharmacy, 020021 Bucharest; \\ ${ }^{2}$ Department of Endocrinology, 'Prof. Dr. Agrippa Ionescu' Clinical Emergency Hospital, 011356 Bucharest; \\ ${ }^{3}$ Department of Anatomy, Faculty of Medicine, 'Carol Davila' University of Medicine and Pharmacy, 020021 Bucharest; \\ Departments of ${ }^{4}$ General Surgery, ${ }^{5}$ Cardiovascular Surgery and ${ }^{6}$ Plastic and Reconstructive Surgery, \\ 'Prof. Dr. Agrippa Ionescu' Clinical Emergency Hospital, 011356 Bucharest; ${ }^{7}$ Department of Plastic and \\ Reconstructive Surgery, Faculty of Medicine, 'Carol Davila' University of Medicine and Pharmacy; \\ ${ }^{8}$ Department of Surgery, 'Carol Davila’ University of Medicine and Pharmacy, 020021 Bucharest; \\ ${ }^{9}$ Department of Surgery, 'Sf. Pantelimon’ Emergency Clinical Hospital, 021659 Bucharest; \\ ${ }^{10}$ Department of Cardiovascular Surgery, Faculty of Medicine, 'Carol Davila' University of Medicine and Pharmacy, \\ 020021 Bucharest; ${ }^{11}$ Department of Cardiovascular Surgery 'Prof. Dr. C. C. Iliescu’ Emergency Institute for \\ Cardiovascular Diseases, 022328 Bucharest; ${ }^{12}$ Discipline of Pediatric Surgery, Faculty of Medicine, \\ 'Carol Davila' University of Medicine and Pharmacy, 020021 Bucharest; ${ }^{13}$ Department of Pediatric Surgery, \\ Emergency Clinical Hospital for Children 'Marie S. Curie', 41451 Bucharest, Romania
}

Received February 26, 2021; Accepted March 30, 2021

DOI: $10.3892 / \mathrm{etm} .2021 .10204$

\begin{abstract}
Independent Cushing's adrenocorticotropic hormone (ACTH) syndrome can have several causes, including adrenal carcinoma or simple adrenal hyperplasia. Although the distinction between malignant and benign can be effectively made through imaging investigations, in the situation where there are bilateral formations, their hormonal activity is impossible to appreciate via non-invasive techniques. The present study includes the presentation of a clinical case on the basis of which a literature review was made. The clinical case pertains to a 32-year-old patient with ACTH-independent Cushing's syndrome and bilateral adrenal tumor formations leading to the utility of adrenal venous sampling to avoid bilateral adrenalectomy. A literature review was subsequently conducted focusing on articles pertaining to the PICO criteria in order to describe: The diagnosis of adrenal tumor masses, the decision on the type of surgery and most importantly, the impact of adrenal venous sampling in avoiding surgical
\end{abstract}

Correspondence to: Mr. Adrian Tulin, Department of Anatomy, Faculty of Medicine, 'Carol Davila' University of Medicine and Pharmacy, Street Dionisie Lupu 37, 020021 Bucharest, Romania E-mail: dr_2lin@yahoo.com

Key words: Cushing's syndrome, suprarenal vein catheterization, decision-making resection. These interventions severely limit the patients' quality of life.

\section{Introduction}

Cushing's syndrome (CS) is considered a rare and challenging disorder $(1,2)$. It can be classified by the level of adrenocorticotropic hormone (ACTH) in two major subtypes: ACTH-independent with autonomous production of corticoid hormones, and ACTH-dependent with peripheral hyperproduction of corticoid hormones which is dictated by the pituitary gland through hypersecretion of ACTH (3). It is highly important to exclude exogenous causes, more specifically the administration of steroid hormones. There are three major situations which lead to CS: Adrenal adenomas, adrenal carcinomas, and adrenal hyperplasia, excluding a pituitary origin of the syndrome $(4,5)$.

In all these situations, the standard treatment is surgical resection of the adenomatous gland when there is unilateral involvement or bilateral suprarenalectomy, when both glands have functional active adenomas (6). Bilateral adrenalectomy is associated with a decrease in the patient's quality of life, requiring mineralocorticoid and glucocorticoid replacement therapy. Therefore, effective investigations are crucial to diagnose preoperatively the origin of hyperproduction of the adrenal gland. The computed tomography scan can identify bilateral adrenal adenomas, with three possible scenarios: Hyperproductive bilateral cortisol tumors, adrenal macronodular hyperplasia or hyperproductive unilateral cortisol tumor, 
and a non-functional contralateral tumor (6). In the case that primary hyperaldosteronism adenoma is suspected, adrenal scintigraphy is considered a safe and effective diagnostic solution (7).

Currently, the gold standard diagnostic tool for patients with bilateral adrenal adenoma and ACTH-independent CS is bilateral adrenal venous sampling and the dosage of cortisol levels. Value comparison provides definitive results in $99.9 \%$ of cases (8). This diagnostic procedure is an invasive one that involves a number of risks for the patient and limitations for the physician. The method is based on left adrenal vein cannulation which is difficult intervention due to the fact that the vein is often narrow with a sinuous route being difficult to locate.

\section{Research methods}

This paper exemplifies the importance of this diagnostic procedure through a clinical case described in the next paragraph. To perform a pertinent review of the literature on the described topic, successive searches were obtained from the PubMed database between 1 January, 1995 and 1 October, 2020 using the keywords: 'Adrenal vein sampling' AND 'adrenal mass imaging' AND 'ACTH non-dependent Cushing syndrome'. The search was refined for original articles and rare clinical cases written only in English. A total of 43 articles were identified. After manual selection that met the PICO criteria, 13 articles were eliminated as such: Incomplete data (4 articles), 7 articles did not have the full text available and 2 articles did not incorporate a study on bilateral suprarenal adenomas and as such were not introduced in the analysis. A total of 30 articles were selected and 22 were selected for discussion, which will be described in detail subsequently in the study.

The study was conducted according to the World Medical Association Declaration of Helsinki, using a protocol approved by the local Bioethics Committee from 'Prof. Dr. Agrippa Ionescu' Clinical Emergency Hospital (Bucharest, Romania). The patient previously signed informed written consent about hospitalization, treatment and a future publication of data.

\section{Case presentation}

This is the case of a 32-year-old female patient who presented to the hospital for progressive weight gain over the previous 6 months. The clinical examination identified an abdominal distribution of adipose tissue, cutaneous fragility, stretch marks on the abdomen and lower limbs, hirsutism, and oligomenorrhea.

Common laboratory tests confirmed the presence of leukocytosis with neutrophilia and hypoglycemia (unusual), hypercholesterolemia and D-vitamin insufficiency, which are characteristic (9).

The hormonal profile was obtained: Blood cortisol values, $23.05 \mu \mathrm{g} / \mathrm{dl}$ (6.7-22.6); cortisol values at 24:00 h, $4.56 \mu \mathrm{g} / \mathrm{dl}$. The circadian rate of cortisol hormone secretion was maintained. ACTH value was $1.21 \mathrm{pg} / \mathrm{ml}$ and urinary free cortisol (UFC) value was $1,448 \mathrm{nmol} / 24 \mathrm{~h}[52.48 \mu \mathrm{g} / \mathrm{dl}]$. The values obtained after the $1 \mathrm{mg}$ overnight dexamethasone test were: Cortisol, $10.47 \mu \mathrm{g} / \mathrm{dl}$ [288.9 nmol/l]; follicle-stimulating hormone
(FSH), $5.72 \mathrm{mUI} / \mathrm{ml}$; luteinizing hormone (LH), $6.04 \mathrm{mUI} / \mathrm{ml}$; estradiol, $28.6 \mathrm{pg} / \mathrm{ml}$ and prolactin (PRL), $13.16 \mathrm{ng} / \mathrm{ml}$, indicating intact hypophyseal ovarian axis. Osteopenia was also confirmed.

After the 24-h blood pressure monitoring was performed, the presence of a dipper profile was confirmed: The average diurnal value was $126 / 80 \mathrm{mmHg}$ and nocturnal value of 100/71 mmHg.

A glucose tolerance test was performed which revealed glycemia value of $75 \mathrm{mg} / \mathrm{dl}$ at $2 \mathrm{~h}$. Echocardiography excluded the presence of atrial myxoma or other cardiovascular abnormalities.

The abdominal contrast-enhanced computed tomography scan showed nodular lesions in the adrenal glands- $7 \mathrm{~mm}$ on the right and $37 \mathrm{~mm}$ on the left which were probably adenoids with low lipid substrate (32 HU-Hounsfield unit densities) (Fig. 1).

Subsequent head magnetic resonance imaging showed the hypophysis with low 3-4 mm hypocaptant areas in the right and left adenohypophysis with non-homogeneous loading with intravenous contrast (possibly suggesting microadenomas).

The diagnosis of an ACTH-independent CS was confirmed due to adrenal adenomas.

In order to accurately identify the hyperproductive adenoma for surgical resection, supra-selective hormone dosage from both of the suprarenal veins was obtained and the lateralization index was calculated. Firstly, the right femoral vein was used as an entry point, after that the right suprarenal vein was catheterized followed by the left suprarenal vein and blood samples for hormone dosage were obtained (Fig. 2).

The following cortisol values were confirmed: Right adrenal vein, $5.91 \mu \mathrm{g} / \mathrm{dl}$ and left adrenal vein, $>60 \mu \mathrm{g} / \mathrm{dl}$. These values confirmed the ACTH-independent CS due to a left adrenal adenoma. Surgery was decided and a left laparoscopic adrenalectomy was performed in January, 2018 (Table I).

The 1-year follow-up was favorable. The patient was started on supplements with vitamin D and the osteoporosis was recovered completely.

\section{Current diagnostic criteria and surgical treatment options}

The use of high-resolution imaging has led to an increased rate of incidental detection of unilateral adrenal masses, which most commonly are benign non-functioning adrenal adenomas. Patients with bilateral adrenal masses are rarely encountered. Patients with bilateral adrenal tumors can present different clinical manifestations ranging from asymptomatic to multi-organ dysfunctions (10).

In the patient with ACTH-independent Cushing's syndrome, CT examination is the initial imaging procedure with first intention. Abdominal MRI should be conducted when there is ambiguity as it is not cost-effective. A retrospective study that included 99 patients (48 women and 51 men) reported the imaging characteristics of their 122 adrenal masses (10). Patients were either operated on to obtain a tissue sample from the tumors or were enrolled in a follow-up program with regular CT evaluations (10). CT scan images were recorded from all the patients, both native (without intravenous contrast substance) and after administration of $120 \mathrm{ml}$ of intravenous contrast substance (10). Subsequently, the images were analyzed after mean attenuation, calculating 


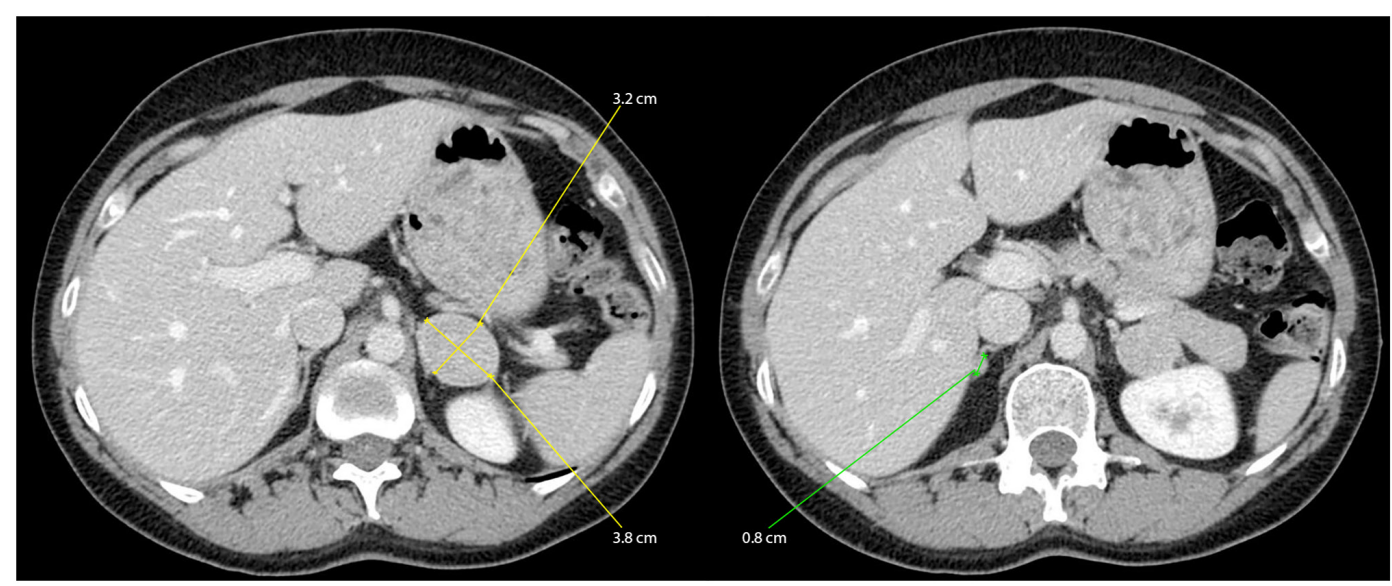

Figure 1. Abominal CT with IV contrast: Similar nodular lesions in both of the adrenal glands were identified.
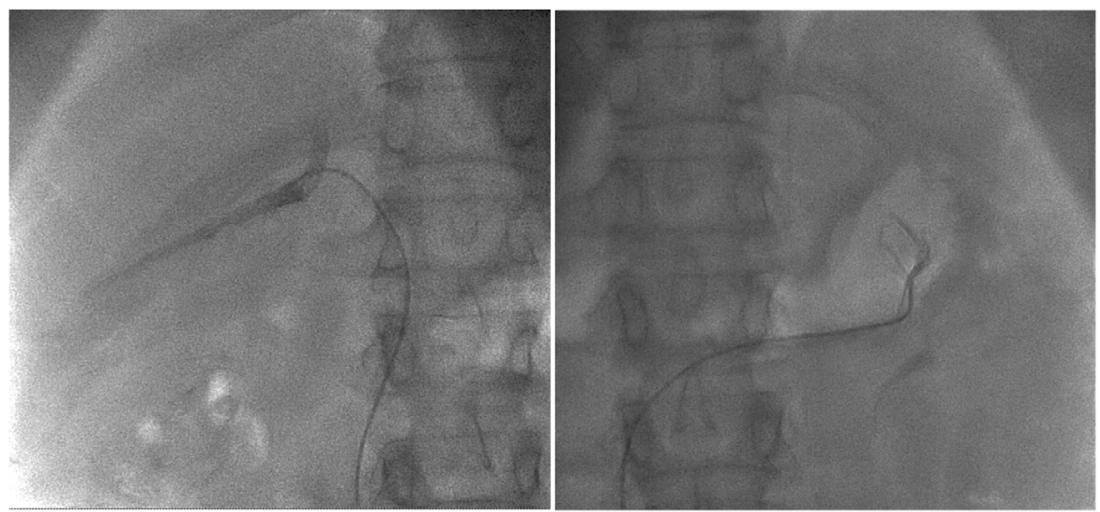

Figure 2. Radiologic aspect during catheterization of the suprarenal veins.

Table I. Postoperative cortisol values.

\begin{tabular}{lr}
\hline Date & Cortisol $(133-537 \mathrm{nmol} / \mathrm{l})$ \\
\hline 02.2018 & $8 \mathrm{nmol} / \mathrm{l}=0.28 \mu \mathrm{g} / \mathrm{dl}$ \\
02.2018 & $106.3 \mathrm{nmol} / \mathrm{l}=3.85 \mu \mathrm{g} / \mathrm{dl}$ \\
03.2018 & $141.7 \mathrm{nmol} / \mathrm{l}=5.13 \mu \mathrm{g} / \mathrm{dl}$ \\
03.2018 & $148.4 \mathrm{nmol} / \mathrm{l}=5.37 \mu \mathrm{g} / \mathrm{dl}$ \\
04.2018 & $272.2 \mathrm{nmol} / \mathrm{l}=9.86 \mu \mathrm{g} / \mathrm{dl}$ \\
05.2018 Stop Prednisone & $360 \mathrm{nmol} / \mathrm{l}=13.04 \mu \mathrm{g} / \mathrm{dl}$
\end{tabular}

relative percentage washout (RPW) and absolute percentage washout (APW) (10).

The specificity and sensitivity of identifying malignant tumors with these criteria were 98 and $100 \%$, respectively. The attenuation of $43 \mathrm{HU}$ was used as the threshold to distinguish benign from malignant lesions. Thus, the surgical approach must be guided by imaging suspicion (10).

Adrenal hyperplasia is a common cause of this disease (11). This is followed by infection, metastasis or lymphoma, while bilateral tumors usually evolve as pheochromocytomas $(12,13)$. Tian et al highlighted the etiologies of bilateral adrenal lesions in a study performed on 260 patients. Authors of that study showed that bilateral adrenal hyperplasia was identified in
75 cases, followed in frequency by bilateral adrenal adenomas, metastatic carcinoma, discordant bilateral adrenal lesions, bilateral pheochromocytomas, among others. A mere 5 patients were diagnosed with CS which consisted of only $2 \%$ of all cases (12). Zhou et al described in their study 18 patients with bilateral adrenal masses from 565 patients with adrenal tumors. Of the 18 patients, only 1 patient presented CS (14).

The therapeutic management of patients with bilateral adrenal masses and CS is challenging for the endocrinologist, but also for the general surgeon. Surgical excision of the adrenal glands must be avoided in the absence of a certain diagnosis. Macronodular bilateral adrenal hyperplasia in a patient with ACTH-independent Cushing syndrome is one of the rarest causes of cortisol hyperproduction (5).

When a patient is diagnosed with bilateral adrenal masses, it is crucial to determine whether both have hormonal activity. High-resolution imaging does not bring important data regarding the differentiation between a hyper-functional adenoma and a non-functional one. Direct hormonal dosing from the adrenal vein has been reported as an effective way to differentiate these tumor masses in ACTH-independent Cushing syndrome (15).

Less than $2 \%$ of all cases of hypercorticism exist in the form of two concomitant adrenal mass tumors, therefore the possibility that only one of the tumors was responsible for the Cushing syndrome was high in our patient (16). 
However, improvements have been made and The Society of Endocrinology recommends ultra-selective hormone dosage of blood obtained directly from both the adrenal veins as a standard diagnostic technique when such cases are encountered (5). However, few studies have described the utility and effectiveness of this technique. The vast majority of published articles on this subject are case studies, while major prospective randomized trials are lacking.

However, Funder et al demonstrated the effectiveness of this diagnostic technique, using a relatively small batch of only 10 patients. Their study made a reference to the threshold values for cortisol dosage. Thus the ratio between cortisol values from the adrenal vein (AV) and peripheral vein (PV) $>6.5$ is highly suggestive of a hyperproductive adenoma, whereas a ratio value $<3.3$ is consistent with the presence of a non-functional nodule. Regarding the percentage of lateralization, those authors identified that the presence of a gradient $>2.3$ suggests the presence of a unilateral hyperfunctional tumor while the presence of a gradient $\leq 2$ raises the suspicion of hyperproductive bilateral nodules (16).

The results of this groundbreaking study have recently been questioned by Acharya et al (17) who, using criteria of Funder et al (16), failed to confirm the lateralization of adrenal adenomas, probably due to patient selection criteria as mentioned in the study (17). Instead, the group focused on the morphology identified at the computer tomography scan, and surgically excised accordingly the larger suprarenal multinodular gland, thus avoiding a life-altering bilateral suprarenalectomy. The final results were satisfactory. Identical results were obtained and discussed by Iacobone et al (18) and Debillon et al (19). From our point of view, long-term confirmation of the effectiveness of this method is required; however, the authors from the aforementioned studies did not report a proper follow-up. Additionally, it is imperative to study the improvement of the quality of life of the patients (20).

The contraindications of this procedure are coagulation disorders (21), blood hypertension, contrast substance allergy, pregnancy and kidney failure (22). The association between Cushing's syndrome and chronic kidney disease (CKD) is known and accepted by researchers (23), and is presented in many studies. The presence of blood hypertension leads to hypertensive nephrophathy $(24,25)$.

Unilateral adrenal venous sampling has been employed by multiple endocrinology societies as the optimal diagnostic tool when bilateral adenomas are encountered and associated with an ACTH-independent CS $(16,26)$.

Scintigraphy has a limited usage as frequently both of the adenomas capture the tracer and the clinician cannot distinguish which of them needs resecting (27).

In our case, the resection was performed by a multidisciplinary team, which encompassed a general and vascular surgeon. Postoperatively, the parietal wounds after laparoscopy were treated with a gel with polyhexanidine, due to its antiseptic properties (28).

Although the adrenal venous sampling technique is reserved for diagnosis it is nonetheless an invasive procedure. Thus, attention needs to be paid to the possible immediate complications and the medical staff should be prepared if they arise (29).

Complications may be severe, so it is highly important to have a vascular surgery department in the center where the investigation is performed. The complications encountered when this procedure is performed include hemorrhage with retroperitoneal hematoma, adrenal infarction and hematoma at the puncture site $(30,31)$.

The risk of rupturing the adrenal vein during this procedure is $<1 \%$ (32).

In conclusion, when bilateral adrenal tumors are encountered a differential diagnosis is difficult to obtain. In the case of an associated ACTH-independent Cushing syndrome, scintigraphy has a limited utility. Hormone dosage from venous blood of both adrenal veins is a key step in confirming the presence of a lateral secretion of cortisol. Due to the rarity of this pathology, it would be necessary to have an international database in order to obtain data with the statistical value that would allow optimization of the therapeutic management of these patients. In our case, the intervention was performed by a multidisciplinary team, general and vascular surgeons. Postoperatively, the parietal wounds after laparoscopy were treated with a gel with polyhexanidine, due to its antiseptic properties. Although this technique is reserved for diagnosis it is nonetheless an invasive procedure, and attention should be paid to the possible immediate complications and the medical staff should be prepared if they arise.

\section{Acknowledgements}

Not applicable.

\section{Funding}

No funding was received.

\section{Availability of data and materials}

The datasets used and/or analyzed during the current study are available from the corresponding author on reasonable request.

\section{Authors' contributions}

RT, RIS, CRJ and AT made major contribution to the conception and design of the study. RIS, AA, BS, LFT, AT, EM, CRJ and OS, provided study material or patients, collected the data and analyzed the datasets. RIS, RT, LFT, AA, BS, EM, AT and OS wrote the manuscript. RT, AT, RIS and CRJ confirmed the authenticity of all the raw data and RT, RIS and CRJ critically revised the manuscript. All authors read and approved the final manuscript. The contribution of all the authors on this article is greatly valued and appreciated.

\section{Ethics approval and consent to participate}

The study was conducted according to the World Medical Association Declaration of Helsinki, using a protocol approved by the local Bioethics Committee from 'Prof. Dr. Agrippa Ionescu' Clinical Emergency Hospital (Bucharest, Romania).

\section{Patient consent for publication}

The patient previously signed informed written consent about hospitalization, treatment and a future publication of data. 


\section{Competing interests}

The authors declare that they have no competing interests.

\section{References}

1. Pappachan JM, Hariman C, Edavalath M, Waldron J and Hanna FW: Cushing's syndrome: A practical approach to diagnosis and differential diagnoses. J Clin Pathol 70: 350-359, 2017

2. Sharma ST, Nieman LK and Feelders RA: Cushing's syndrome: Epidemiology and developments in disease management. Clin Epidemiol 7: 281-293, 2015.

3. Stewart PM: The adrenal cortex. In: Kronenberg HM, Melmed S, Polonsky KS and Larsen PR (eds). Williams textbook of endocrinology. 11th edition. Saunders Elsevier, Philadelphia, PH, pp445-503, 2008.

4. Dinneen SF, Carney JA, Carpenter PC, Grant CS and Young WF Jr: Acth-independent Cushing's syndrome: Bilateral cortisol-producing adrenal adenomas. Endocr Pract 1: 77-81, 1995.

5. De Venanzi A, Alencar GA, Bourdeau I, Fragoso MC and Lacroix A: Primary bilateral macronodular adrenal hyperplasia. Curr Opin Endocrinol Diabetes Obes 21: 177-184, 2014.

6. Domino JP, Chionh SB, Lmanto D, Katara AN, Rauff A and Cheah WK: Laparoscopic partial adrenalectomy for bilateral cortisol-secreting adenomas. Asian J Surg 30: 154-157, 2007.

7. Yasuda A, Seki T, Ito K, Takagi A, Watanabe D, Nakamura N, Hanai K, Terachi T, Maekawa T, Sasano H and Fukagawa M: A rare case of Cushing's syndrome due to bilateral adrenocortical adenomas. Tokai J Exp Clin Med 39: 158-165, 2014.

8. Stewart PM and Allolio B: Adrenal vein sampling for primary aldosteronism: Time for a reality check. Clin Endocrinol (Oxf) 72: 146-148, 2010.

9. Stanescu AMA, Grajdeanu IV, Iancu MA, Pantea Stoian A Bratu OG, Socea B, Socea LI and Diaconu CC: Correlation of oral vitamin D administration with the severity of psoriasis and the presence of metabolic syndrome. Rev Chim 69: 1668-1672, 2018.

10. Blake MA, Kalra MK, Sweeney AT, Lucey BC, Maher MM, Sahani DV, Halpern EF, Mueller PR, Hahn PF and Boland GW: Distinguishing benign from malignant adrenal masses: Multi-detector row CT protocol with 10-minute delay. Radiology 238: 578-585, 2006

11. Lomte N, Bandgar T, Khare S, Jadhav S, Lila A, Goroshi M, Kasaliwal R, Khadilkar K and Shah NS: Bilateral adrenal masses: A single-centre experience. Endocr Connect 5: 92-100, 2016.

12. Tian Q, Zhang ST, Gao HW, Lu R, Yang J, Wang HN and Hong TP: The etiological analysis of 260 hospitalized cases with bilateral adrenal lesions. Zhonghua Yi Xue Za Zhi 99: 1246-1250, 2019 (In Chinese).

13. Bratu OG, Marcu RD, Socea B, Neagu TP, Diaconu CC, Scarneciu I, Turcu FL, Radavoi GD, Bratila E, Berceanu C and Spinu AD: Immunohistochemistry particularities of retroperitoneal tumors. Rev Chim 69: 1813-1816, 2018.

14. Zhou J, Ye D, Wu M, Zheng F, Wu F, Wang Z and Li H: Bilateral adrenal tumor: Causes and clinical features in eighteen cases. Int Urol Nephrol 41: 547-551, 2009.

15. Young WF Jr, du Plessis H, Thompson GB, Grant CS, Farley DR, Richards ML, Erickson D, Vella A, Stanson AW, Carney JA, et al: The clinical conundrum of corticotropin-independent autonomous cortisol secretion in patients with bilateral adrenal masses. World J Surg 32: 856-862, 2008

16. Funder JW, Carey RM,Fardella C, Gomez-Sanchez CE, ManteroF, Stowasser M, Young WF Jr and Montori VM; Endocrine Society: Case detection, diagnosis, and treatment of patients with primary aldosteronism: An endocrine society clinical practice guideline. J Clin Endocrinol Metab 93: 3266-3281, 2008.

17. Acharya R, Dhir M, Bandi R, Yip L and Challinor S: Outcomes of adrenal venous sampling in patients with bilateral adrenal masses and ACTH-independent Cushing's syndrome. World J Surg 43: 527-533, 2019.
18. Iacobone M, Albiger N, Scaroni C, Mantero F, Fassina A, Viel G, Frego $\mathrm{M}$ and Favia G: The role of unilateral adrenalectomy in ACTH-independent macronodular adrenal hyperplasia (AIMAH). World J Surg 32: 882-889, 2008.

19. Debillon E, Velayoudom-Cephise FL, Salenave S, Caron P, Chaffanjon P, Wagner T, Massoutier M, Lambert B, Benoit M, Young $\mathbf{J}$, et al: Unilateral adrenalectomy as a first-line treatment of Cushing's syndrome in patients with primary bilateral macronodular adrenal hyperplasia. J Clin Endocrinol Metab 100: 4417-4424, 2015

20. Răducu L, Avino A, Purnichescu Purtan R, BalcangiuStroescu AE, Bălan DG, Timofte D, Ionescu D and Jecan CR: Quality of life in patients with surgically removed skin tumors. Medicina (Kaunas) 56: 66, 2020

21. Laslo CL, Pantea Stoian A, Socea B, Paduraru DN, Bodean O, Socea LI, Neagu TP, Stanescu AMA, Marcu D and Diaconu C: New oral anticoagulants and their reversal agents. J Mind Med Sci 5: 195-201, 2018.

22. Gaman MA, Dobrica EC, Pascu EG, Cozma MA, Epingeac ME, Gaman AM, Pantea Stoian AM, Bratu OG, and Diaconu CC: Cardio metabolic risk factors for atrial fibrillation in type 2 diabetes mellitus: Focus on hypertension, metabolic syndrome and obesity. J Mind Med Sci 6: 157-161, 2019.

23. Li X, Xiang X, Hu J, Goswami R, Yang S, Zhang A, Wang Y, $\mathrm{Li} \mathrm{Q}$ and $\mathrm{Bi} \mathrm{X}$ : Association between serum cortisol and chronic kidney disease in patients with essential hypertension. Kidney Blood Press Res 41: 384-391, 2016.

24. Mandita A, Timofte D, Balcangiu-Stroescu AE, Balan D, Raducu L, Tanasescu MD, Diaconescu A, Dragos D, Cosconel CI, Stoicescu SM and Ionescu D: Treatment of high blood pressure in patients with chronic renal disease. Rev Chim Buchar 70: 993-995, 2019.

25. Balcangiu-Stroescu AE, Tanasescu MD, Diaconescu A, Raducu L, Constantin AM, Balan DG, Tarmure V and Ionescu D: Cardiovascular comorbidities, inflammation and serum albumin levels in a group of hemodialysis patients. Rev Chim 69: 926-929, 2018.

26. Nishikawa T, Omura M, Satoh F, Shibata H, Takahashi K, Tamura $\mathrm{N}$ and Tanabe A; Task Force Committee on Primary Aldosteronism, The Japan Endocrine Society: Guidelines for the diagnosis and treatment of primary aldosteronism-the Japan endocrine society 2009. Endocr J 58: 711-721, 2011.

27. Oki K, Yamane K, Sakashita Y, Kamei N, Watanabe H, Toyota N, Shigeta M, Sasano H and Kohno N: Primary aldosteronism and hypercortisolism due to bilateral functioning adrenocortical adenomas. Clin Exp Nephrol 12: 382-387, 2008.

28. Raducu L, Balcangiu-Stroescu AE, Stanescu II, Tanasescu MD, Cozma CN, Jecan CR and Badita DG: Use of polyhexanidine in treating chronic wounds. Rev Chim 68: 2112-2113, 2017.

29. Paduraru DN, Scanteie C, Bolocan A, Andronic O, Morar A, Ghervan C, Ciunt R, Socea B, Bratu OG, Dragomir LM, et al: Pasireotide after surgery for persistent Cushing's disease. Mod Med 26: 227-231, 2019.

30. Marcu RD, Diaconu CC, Constantin T, Socea B, Ionita-Radu F, Mischianu DLD and Bratu OG: Minimally invasive biopsy in retroperitoneal tumors. Exp Ther Med 18: 5016-5020, 2019.

31. Marcu DR, Ionita-Radu F, Iorga LD, Manea M, Socea B, Scarneciu I, Isvoranu G, Costache R, Diaconu CC and Bratu OG: Vascular involvement in primary retroperitoneal tumors. Rev Chim 70: 445-448, 2019.

32. Rossi GP, Barisa M, Allolio B, Auchus RJ, Amar L, Cohen D, Degenhart C, Deinum J, Fischer E, Gordon R, et al: The adrenal vein sampling international study (AVIS) for identifying the major subtypes of primary aldosteronism. J Clin Endocrinol Metab 97: 1606-1614, 2012

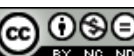

This work is licensed under a Creative Commons Attribution-NonCommercial-NoDerivatives 4.0 International (CC BY-NC-ND 4.0) License. 